\title{
Originales
}

\section{Trasplante hepático: influencia de los factores dependientes del donante}

\author{
GEMMA SELLER-PÉREZ, MANUEL E. HERRERA-GUTIÉRREZ, MIGUEL LEBRÓN-GALLARDO, \\ JOSÉ MORENO-QUINTANA, ESTHER BANDERAS-BRAVO \\ Y GUILLERMO QUESADA-GARCÍA
}

Servicio de Cuidados Críticos y Urgencias. Complejo Universitario Hospitalario Carlos Haya. Málaga. España.

Objetivo. Detectar características del donante relacionadas con la funcionalidad del injerto tras el trasplante ortotópico hepático (TOH).

Diseño. Estudio de cohortes retrospectivo.

Ámbito. Unidad de cuidados intensivos polivalente.

Pacientes. Se incluyó a 145 pacientes trasplantados y sus correspondientes donantes.

Intervenciones. Ninguna.

Variables principales de interés. En el donante se analizan predictores de gravedad como la edad, la hipernatremia y la infección; las principales variables dependientes del receptor fueron infección, síndrome de disnea del adulto, shock, insuficiencia renal, disfunción primaria del injerto y mortalidad.

Resultados. El $71,7 \%$ de los receptores eran varones, con una media de edad de 54,5 $\pm 9,9$ años; en Child B el $66,2 \%$ y en Child C el $19,3 \%$; Meld, $14,6 \pm 4,8$; APACHE II, $17,3 \pm 4,9$. El $64,1 \%$ de los donantes eran varones, con una media de edad de 42,3 \pm 16,3 años; APACHE II, 22,3 $\pm 5,8$. La edad del donante $>65$ años se relaciona con un máximo de aspartato aminotransferasa (AST) más elevado en el receptor, pero no con un aumento de complicaciones o mortalidad. Ningún otro factor se relacionó con la evolución o el pronóstico. En $18(12,4 \%)$ receptores se diagnosticó infección en

Este estudio se ha realizado sin financiación externa. Resultados provisionales del estudio fueron presentados en el congreso anual de la SEMICYUC en 2006, pero no han sido publicados.

Correspondencia: Dra. G. Seller Pérez.

Servicio de Cuidados Críticos y Urgencias.

Complejo Universitario Hospitalario Carlos Haya.

Avda. Carlos Haya, s/n. 29018 Málaga. España.

Correo electrónico: gemmaseller@gmail.com

Manuscrito aceptado el 15-2-2008 el postoperatorio; la incidencia en los que recibieron un órgano de donante con infección no fue diferente de la de aquellos cuyo donante no estaba infectado (el 14,6 frente al 11,5\%; $p>0,05$ ).

Conclusiones. No se ha detectado ninguna característica del donante relacionada con la funcionalidad del injerto ni con la aparición de complicaciones en el receptor durante el postoperatorio inmediato. La edad > 65 años y la bacteriemia documentada y adecuadamente tratada en el donante no suponen un riesgo para la viabilidad hepática postrasplante.

PALABRAS CLAVE: Trasplante hepático. Selección de donantes. Mortalidad.

\section{LIVER TRANSPLANTATION: INFLUENCE OF DONOR-RELATED FACTORS}

Objective. To detect donor characteristics related to graft function after orthotopic liver transplantation (OLT).

Design. Retrospective cohort study.

Context. Polyvalent intensive care unit.

Patients. 145 liver transplant recipients and their respective donors.

Interventions. None.

Main variables of interest. In donors: age, hypernatremia, and infection. In recipients: reperfusion syndrome, coagulopathy, infection, ARDS, shock, kidney failure, primary graft dysfunction, and mortality.

Results. $71.7 \%$ of recipients were male. Mean recipient age was $54.5 \pm 9.9$ years; $66.2 \%$ of patients were classified as Child $B$ and and $19.3 \%$ as Child C. The mean model for end-stage liver disease (MELD) score was $14.6 \pm 4.8$ and the mean APACHE II score was $17.3 \pm 4.9$. A total of $64.1 \%$ of the donors were male. Mean donor age was 
$42.3 \pm 16.3$ years, and mean APACHE II score was $22.3 \pm 5.8$. Donor age $>65$ years was associated to higher recipient aspartate aminotransferase (AST) levels but not to increased complications or mortality. No other donor factors (including age, sex, serum sodium, severity level, transfusions, hemodynamic alterations, renal dysfunction, or infection) were associated to evolution or prognosis. Infection was diagnosed in 18 recipients $(12.4 \%)$ in the postoperative period; the incidence of infection in recipients that received an organ from infected donors was not different from those that received an organ from an uninfected donor (14.6\% versus $11.5 \%$; $p>0.05$ ).

Conclusions. We detected no donor characteristics related to graft function or the appearance of complications in recipients during the immediate postoperative period. Donor age $>65$ years and documented but appropriately treated bacteremia posed no risk for the viability of the liver after transplantation.

KEY WORDS: Liver transplantation. Donor selection. Mortality.

\section{INTRODUCCIÓN}

El trasplante hepático se ha consolidado desde el final del pasado siglo como la solución a diversos problemas hepáticos graves y no reversibles, tanto agudos como crónicos, con supervivencias cercanas al $83 \% 1$ año tras el trasplante ${ }^{1}$.

El éxito del trasplante depende de una conjunción de hechos, entre los que los factores dependientes del donante son el primer eslabón cronológico.

Durante su estancia en la unidad de cuidados intensivos, las alteraciones clínicas que se desarrollan en los donantes de órganos son muchas y variadas, entre las que destacan los problemas de mantenimiento referidos a hemodinámica o los trastornos analíticos ${ }^{2}$.

Estas incidencias durante la fase previa a la extracción de órganos tienen un papel preponderante, y algunas de ellas se han referido como inductoras bien de insuficiencia del hígado trasplantado (como la esteatosis hepática en el donante ${ }^{3}$ ), bien de mortalidad precoz del receptor, como la prolongación del tiempo de isquemia total del órgano ${ }^{4}$.

Nuestro objetivo es estudiar la relación entre las variables consideradas de interés relativas al donante que pudieran influir en la funcionalidad del hígado en el postrasplante inicial.

\section{MATERIAL Y MÉTODOS}

Estudio de cohortes retrospectivo de los trasplantes hepáticos realizados en el Hospital Carlos Haya de Málaga con donantes originados en el mismo centro, que es de tercer nivel y atiende todo tipo de patologías. El programa de trasplante hepático se inició en el año 1997, y se han realizado, hasta el momento del cierre de recogida de datos para el estudio, 422 trasplantes hepáticos, de los cuales 145 recibieron un órgano extraído en nuestro centro.

Las variables de interés analizadas en el donante fueron la edad, la hipernatremia y la presencia de infección. La edad de los donantes se categorizó en $\leq$ 65 o > 65 años. Consideramos hipernatremia si el sodio sérico era $\geq 150 \mathrm{mEq} / \mathrm{l}$. Se recogió el dato de cultivo positivo en cualquier localización, especificándose el germen correspondiente.

También se recogieron para el estudio y el análisis otras variables independientes, como sexo, causa que desencadenó la muerte encefálica (traumatismo craneoencefálico [TCE], accidente cerebrovascular [ACV] isquémico o hemorrágico o anoxia cerebral), nivel de gravedad medido por APACHE II ${ }^{5}$ al ingreso en los donantes que permanecieron ingresados 24 h o más o aparición durante su ingreso de diabetes insípida neurogénica, fiebre (temperatura $>38^{\circ} \mathrm{C}$ ) e hipotensión (presión arterial sistólica $[\mathrm{PAS}]<100$ mmHg durante más de $1 \mathrm{~h}$, no relacionada con el momento del enclavamiento). Se recogieron asimismo la mayor concentración sérica de creatinina alcanzada $(\mathrm{mg} / \mathrm{dl})$ y la de sodio previa a la extracción $(\mathrm{mEq} / \mathrm{l})$.

El tratamiento al que se sometieron también se analizó, en concreto el uso de hemoderivados (sangre, plasma o plaquetas) y de fármacos vasoactivos (dopamina, dobutamina, noradrenalina o adrenalina). Por último se recogió el tiempo de estancia en la unidad de los donantes.

Hemos registrado otras variables independientes en el receptor que pudieran afectar al resultado del trasplante, como edad, sexo, etiología del daño hepático (enólico, viral, hepatocarcinoma u otros) y nivel de gravedad medido por la escala Child-Pugh ${ }^{6}$ y por la escala $\mathrm{MELD}^{7}$, tiempo de isquemia total en minutos, nivel de gravedad al ingreso medido por APACHE II y datos analíticos considerados relevantes (aspartato aminotransferasa [AST], amonio, actividad de protrombina y factor $\mathrm{V}$ ).

Las variables de interés analizadas en el receptor (dependientes) se refirieron a complicaciones durante y tras la cirugía, así como estancia y supervivencia.

Como datos de la cirugía, se recogieron desarrollo de síndrome de reperfusión (definido como caída de la $\mathrm{PAS}>30 \%$ en los primeros $5 \mathrm{~min}$ de la reperfusión hepática con una duración $>1$ min) y coagulopatía (entendiendo como tal la alteración de los tiempos de coagulación advertidos por el hematólogo responsable de la intervención y comunicada al equipo quirúrgico, lo cual quedaba reflejado en la hoja de anestesia). Como variables postoperatorias, analizamos desarrollo de fallo primario del injerto, definido según criterios de Ploeg ${ }^{8}$, necesidad de técnica de depuración hepática $\left(\mathrm{MARS}^{\circledR}\right)^{9} \mathrm{y} / \mathrm{o}$ de retrasplante urgente, necesidad de transfusión (tipo de hemoderivado y cantidad en mililitros), aparición de fiebre, presencia de infección documentada (tipo y germen causal), cultivos positivos (localización y germen aislado), desarrollo de insuficiencia renal aguda (IRA) definida como ascenso de creatinina $>1,5 \mathrm{mg} / \mathrm{dl}$, necesidad de uso de técnicas de depuración renal, fallo 
hemodinámico entendido como la necesidad de uso de fármacos vasoactivos, desarrollo de síndrome del distrés respiratorio agudo (SDRA), tiempo de estancia y supervivencia en la unidad.

\section{Análisis estadístico}

Los resultados se muestran como media \pm desviación típica para las variables cuantitativas y como frecuencias absolutas y porcentajes para las cualitativas. Las variables que hacen referencia a tiempo se expresan como mediana y percentiles 25-75.

Para el análisis hemos usado el paquete estadístico SPSS para Windows ${ }^{\circledR}$, aplicando la prueba de la $\mathrm{t}$ de Student (o la de la U de Mann-Whitney cuando el número de casos era <30) para el análisis de variables cuantitativas y la prueba de la $\chi^{2}$ o la de Fisher para las variables cualitativas; se ha establecido un nivel de significación estadística menor del $5 \%(\mathrm{p}<0,05)$.

\section{RESULTADOS}

Se incluyó en el estudio un total de 145 casos apareados: 145 receptores de hígado y sus donantes respectivos.

La media de edad de los donantes fue 42,3 $\pm 16,3$ años; $33(22,7 \%)$ de ellos eran mayores de 60 años: $19(13,1 \%)$ donantes entre 60 y 65 años; $9(6,2 \%)$ entre 66 y 70 , y $5(3,4 \%)$ mayores de 71 años. En cuanto a los receptores, la media de edad fue de 54,5 $\pm 9,9$ años. La causa de la muerte fue TCE en $83(57,2 \%)$, ACV en $59(40,7 \%)$ y anoxia cerebral en $3(2,1 \%)$ casos. La totalidad de los datos demográficos y de gravedad relativos a donantes y receptores se expresan en la tabla 1.

\section{TABLA 1. Datos demográficos de donantes y receptores $(n=145)$}

\begin{tabular}{|lc|}
\hline Donantes & \\
Sexo (varones) & $93(64,1)$ \\
Edad (años) & $42,3 \pm 16,3(17-78)$ \\
APACHE II & $22,3 \pm 5,8(8-37)$ \\
Diagnóstico & $83(57,2)$ \\
$\quad$ Traumatismo craneoencefálico & $59(40,7)$ \\
Accidente cerebrovascular & $3(2,1)$ \\
Anoxia & \\
Receptores & $104(71,7)$ \\
Sexo (varones) & $54,5 \pm 9,9(21-70)$ \\
Edad (años) & $17,3 \pm 4,9(7-32)$ \\
APACHE II & $14,6 \pm 4,8(4-29)$ \\
MELD & $8[5-21](1-336)$ \\
Ventilación mecánica (h) & $4[2,5-6](1-22)$ \\
Estancia en UCI (días) & $12(8,3)$ \\
Mortalidad & $96(66,2)$ \\
Child-Pugh & $28(19,3)$ \\
B & \\
C & $77(53,1)$ \\
Motivo del trasplante ortotópico hepático & \\
Viral & $39(26,9)$ \\
Etanol & $4(2,8)$ \\
Hepatocarcinoma & $25(17,2)$ \\
Otros &
\end{tabular}

Los datos expresan media \pm desviación estándar (intervalo); n (\%), y mediana [rango intercuartílico] (intervalo).
TABLA 2. Datos de la cirugía y el postoperatorio inmediato

\begin{tabular}{|lc|}
\hline Tiempo de isquemia (min) & $429 \pm 130(180-1.140)$ \\
Síndrome de reperfusión & $13(9)$ \\
Coagulopatía durante la cirugía & $23(16,3)$ \\
Hematíes las primeras 24 h & $903 \pm 1.177(0-5.000)$ \\
$\quad$ (cél./ml) & \\
AST máxima & $1.686 \pm 2.618(33-21.206)$ \\
Amonio máximo (mol/l) & $54,4 \pm 50,1(4-511)$ \\
Actividad de protrombina & $46,4 \pm 13,9(17-88)$ \\
$\quad$ mínima (\%) & $35,5 \pm 24,5(5-230)$ \\
Factor V mínimo (\%) & $5(3,4)$ \\
Fallo primario del injerto & $64(44,1)$ \\
Uso de vasopresores & $10(6,9)$ \\
Síndrome de disnea del adulto & $24(16,6)$ \\
Insuficiencia renal aguda & $18(12,4)$ \\
Soporte renal & $4(2,8)$ \\
Retrasplante & $12(8,3)$ \\
Muerte &
\end{tabular}

Los datos expresan media \pm desviación estándar (intervalo) o n (\%).

En los donantes se desarrollaron las siguientes alteraciones clínicas: diabetes insípida neurogénica, $109(75,2 \%)$ pacientes; hipotensión arterial, 101 $(69,7 \%)$; IRA, 12 (8,3\%); hipernatremia previa a la extracción $(\mathrm{Na}>150 \mathrm{mEq} / \mathrm{l}), 57(39,6 \%)$; en 33 $(22,9 \%)$ de éstos se situó en 151-155 mEq/1; en 14 $(9,7 \%)$, en $156-160 \mathrm{mEq} / \mathrm{l}$, y en $10(6,9 \%),>161$ $\mathrm{mEq} / \mathrm{l}$.

Fue necesario el uso de fármacos vasoactivos en $125(86,2 \%)$ donantes; el más frecuentemente utilizado fue noradrenalina, en $88(78,5 \%)$ de estos pacientes, seguida de dopamina en $45(31 \%)$ y dobutamina en $6(4,1 \%)$.

La estancia media de los donantes fue de 2 (1-5) (intervalo, 1-19) días.

En cuanto a los receptores: la complicación postoperatoria más frecuente de las recogidas (insuficiencia hemodinámica, respiratoria o renal) fue el fallo hemodinámico con necesidad de vasopresores en 64 $(44,1 \%)$ pacientes, seguido de IRA en $24(16,6 \%)$, de los que 18 (el 12,4\%; el 75\% de los pacientes con IRA) precisaron soporte renal extracorpóreo (para todos ellos, hemodiafiltración venovenosa continua); $10(6,9 \%)$ pacientes presentaron SDRA.

De los 5 pacientes en que se desarrolló fallo primario del injerto, en $4(2,8 \%)$ fue necesario el retrasplante.

Se utilizó depuración hepática mediante sistema MARS $^{\circledR}$ en 1 paciente con fallo primario del injerto, que era uno de los pacientes que luego fallecieron. La totalidad de los datos referentes a la cirugía y el postoperatorio, incluidos los datos analíticos, se reflejan en la tabla 2.

La estancia media de los pacientes trasplantados se cifró en 4 (2,5-6) (intervalo, 1-22) días.

Fallecieron $12(8,3 \%)$ pacientes, 5 de ellos en situación de fracaso multiorgánico, 3 por problemas hemorrágicos, 2 tras fallo primario del injerto, 1 por daño cerebral severo y 1 por pancreatitis aguda grave.

Analizando el efecto de las variables estudiadas en el donante sobre las complicaciones y la evolución en 
TABLA 3. Relación entre variables de interés en el donante y evolución del postoperatorio en el receptor

\begin{tabular}{|c|c|c|c|c|c|c|}
\hline Edad del donante & $\geq 65$ años & $<65$ años & $\mathrm{p}$ & $\mathrm{Na}<150 \mathrm{mEq} / \mathrm{l}$ & $\mathrm{Na} \geq 150 \mathrm{mEq} / \mathrm{l}$ & $\mathrm{p}$ \\
\hline Síndrome de reperfusión & $12 / 132(9,1)$ & $1 / 9(11,1)$ & NS & $12 / 87(13,8)$ & $1 / 53(1,9)$ & $<0,05$ \\
\hline Coagulopatía & $22 / 132(16,7)$ & $1 / 9(11,1)$ & NS & $18 / 87(20,7)$ & $5 / 53(9,4)$ & NS \\
\hline Hematíes las primeras 24 h (cél./ml) & $916 \pm 1.200$ & $698 \pm 784$ & NS & $1.091 \pm 1.299$ & $609 \pm 896$ & NS \\
\hline AST máxima & $1.523 \pm 2.008$ & $4.132 \pm 6.910$ & $<0,05$ & $1.512 \pm 2.036$ & $1.606 \pm 2.085$ & NS \\
\hline Amonio máximo (mol/l) & $54,5 \pm 51,4$ & $53 \pm 24,9$ & NS & $55,8 \pm 61,6$ & $51,3 \pm 24,7$ & NS \\
\hline Actividad de protrombina (\%) & $46,4 \pm 13,8$ & $47,2 \pm 15,9$ & NS & $46,6 \pm 14,6$ & $46,7 \pm 12,6$ & NS \\
\hline Factor V mínimo (\%) & $35,8 \pm 25,1$ & $32,1 \pm 16,2$ & NS & $31,3 \pm 18,3$ & $42,2 \pm 30,6$ & NS \\
\hline Fallo primario de injerto & $5 / 136(3,4)$ & $0 / 9$ & NS & $3 / 87(3,4)$ & $2 / 57(3,5)$ & NS \\
\hline Uso de vasopresores & $61 / 136(44,9)$ & $3 / 9(33,3)$ & NS & $41 / 87(47,1)$ & $22 / 57(38,6)$ & NS \\
\hline Síndrome de disnea del adulto & $9 / 136(6,6)$ & $1 / 9(11,1)$ & NS & $5 / 87(5,7)$ & $4 / 57(7)$ & NS \\
\hline Insuficiencia renal aguda & $22 / 136(16,2)$ & $2 / 9(22,2)$ & NS & $17 / 87(19,5)$ & $7 / 57(12,3)$ & NS \\
\hline Soporte renal & $17 / 136(12,5)$ & $1 / 9(11,1)$ & NS & $10 / 87(11,5)$ & $7 / 57(12,3)$ & NS \\
\hline Retrasplante & $3 / 135(2,2)$ & $1 / 9(11,1)$ & NS & $1 / 86(1,2)$ & $2 / 57(3,5)$ & NS \\
\hline Muerte & $11 / 136(8,1)$ & $1 / 9(11,1)$ & NS & $8 / 87(9,2)$ & $3 / 57(5,3)$ & NS \\
\hline
\end{tabular}

Los datos expresan media \pm desviación estándar o n/N (\%).

el receptor, ninguna de las recogidas muestra relación con el curso postoperatorio ni con la mortalidad (tablas 3 y 4). Concretamente, la hipernatremia en el donante o su edad avanzada no se han mostrado en nuestra serie como factores de riesgo para el receptor.

En cuanto a las concentraciones de sodio, la falta de significación estadística se mantiene asimismo para los cortes superiores a 155 y $160 \mathrm{mEq} / \mathrm{l}$, y en cuanto a la edad, la superior a 65 años supuso una elevación significativamente mayor de la AST en el receptor, pero sin acompañarse de otras complicaciones ni de una mayor incidencia de fallo primario del injerto $(4.132 \pm 6.910$ frente a $1.523 \pm 2.008 ; \mathrm{p}<0,05)$.

El tiempo de isquemia total no se relacionó de forma clara con ninguna complicación ni con la mortalidad en el postoperatorio. Aunque los pacientes que presentaron fallo primario del injerto mostraron un tiempo de isquemia superior, la diferencia no fue significativa $(500 \pm 145$ frente a $426 \pm 129 \mathrm{~min})$, al igual que quienes requirieron retrasplante $(520 \pm 183$ frente a $426 \pm 129 \mathrm{~min})$ o fallecieron $(487 \pm 145$ frente a $425 \pm 128 \mathrm{~min})$.

De los donantes, $69(47,6 \%)$ tuvieron fiebre durante su estancia, pero ésta no supuso una mayor frecuencia de cultivos positivos o infecciones en el receptor. En $41(28,3 \%)$ donantes se aisló algún germen en los cultivos. En 32 (78\%) de estos 41 donantes sólo se realizó un aislamiento; en $8(19,5 \%)$ dos, y en 1 $(2,5 \%)$, tres aislamientos. La relación de gérmenes aislados se refleja en la tabla 4 .

En cuanto a los receptores, tuvieron fiebre 20 $(13,8 \%)$ pacientes, sin relación con los 41 donantes con algún cultivo positivo (11 [10,6\%] de 104 receptores con donante con cultivo negativo frente a 9 [22\%] de 41 con cultivo positivo; diferencia no significativa).

El hemocultivo en los donantes fue positivo en 11 casos; el aspirado bronquial, en 37 y la orina, en 2. El número de infecciones desarrolladas en el receptor fue independiente de que el donante tuviera o no cultivos positivos (fig. 1).

En $18(12,4 \%)$ de los receptores se diagnosticó alguna infección (6 pacientes tuvieron más de una in- fección), la más frecuente de las cuales fue la neumonía, seguida de la bacteriemia primaria. Las infecciones detalladas y los gérmenes que las causaron se expresan en la tabla 5 .

$\mathrm{Ni}$ el origen del cultivo positivo en el donante (sangre, aspirado bronquial u orina) ni el germen aislado se relacionaron con la aparición de infección en los receptores, en quienes no se aisló ninguno de los gérmenes aislados en el donante correspondiente, en ninguna localización.

La infección en el donante, por otra parte, no supuso tampoco otro tipo de morbilidad en el receptor.

\section{DISCUSIÓN}

El buen funcionamiento de un hígado trasplantado obedece a un conjunto de factores, el primero de los cuales es el estado previo del órgano en el donante, lo que depende de factores del propio donan-

\section{TABLA 4. Gérmenes aislados en el donante}

\begin{tabular}{|l|l|c|}
\hline Aislamiento & \multicolumn{1}{|c|}{ Germen } & Casos \\
\hline Aspirado bronquial & Acinetobacter & 6 \\
& Klebsiella & 5 \\
& Staphylococcus aureus & 4 \\
& Haemophilus & 4 \\
& Enterobacter & 4 \\
& Pseudomonas & 2 \\
& Streptococcus & 2 \\
& Serratia & 2 \\
& Citrobacter & 2 \\
Sangre $(\mathrm{n}=12)$ & Otros gérmenes & 4 \\
& Staphylococcus aureus & 2 \\
& Staphylococcus epidermidis & 2 \\
& Enterococcus & 2 \\
& Streptococcus & 2 \\
& Pseudomonas & 1 \\
& Acinetobacter & 1 \\
& Enterobacter & 1 \\
& Proteus & 1 \\
Orina $(\mathrm{n}=4)$ & Acinetobacter & 1 \\
& Enterococcus & 1 \\
& Serratia & 1 \\
& Escherichia coli & \\
& &
\end{tabular}




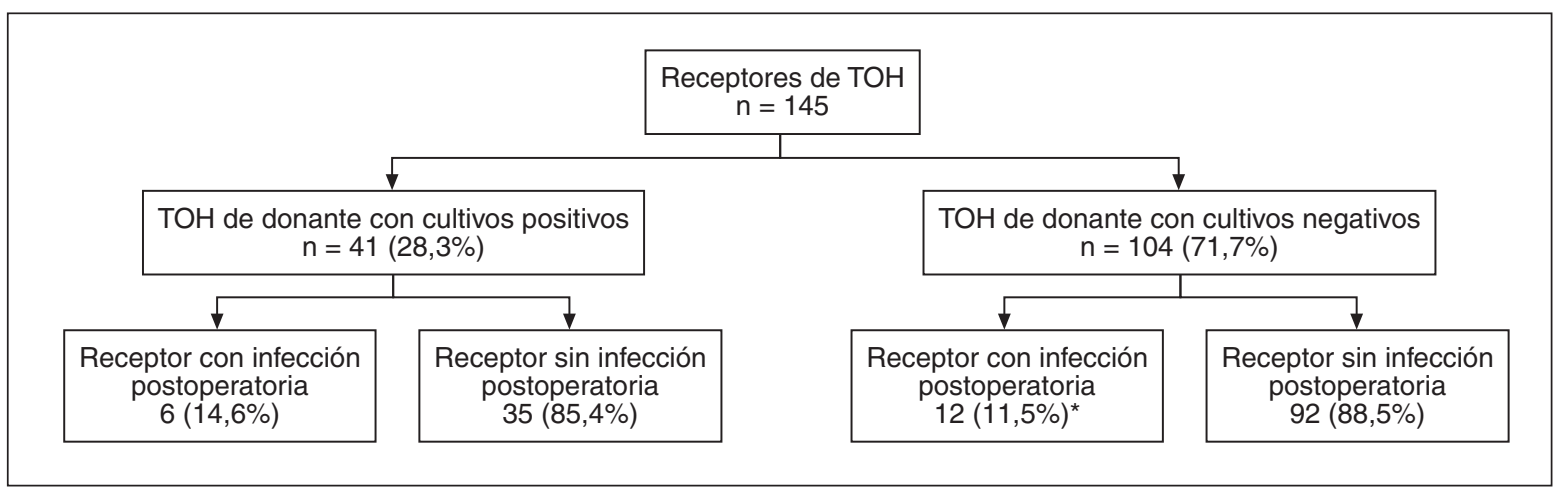

Figura 1. Relación entre la aparición de cultivos positivos en el donante e infección en el receptor. TOH: trasplante ortotópico hepático. * Diferencias no significativas.

te, como la edad o el curso de infección, o del mantenimiento del órgano en el proceso previo a la extracción (shock, hipernatremia). En tercer lugar, son de importancia los eventos producidos durante el acto quirúrgico y, por último, las complicaciones que puedan surgir en el receptor en el período posterior al implante del hígado, una vez el acto quirúrgico ha finalizado.

Teniendo en cuenta la diversidad de factores que pueden estar implicados en que un hígado llegue a funcionar correctamente después de su implante, nosotros hemos intentado hacer una aproximación desde la perspectiva de la influencia que puede tener el mantenimiento del donante en el funcionamiento ulterior del hígado trasplantado y las complicaciones desarrolladas en el receptor de ese órgano.

Para lograr este fin, estudiamos a cada donante de órganos mantenido en nuestra unidad cuyo hígado fue implantado a un receptor incluido en nuestro programa de trasplantes que asimismo pasó el postoperatorio inmediato en dicha unidad hasta su alta o fallecimiento.

\section{TABLA 5. Tipo de infección y gérmenes aislados en el receptor}

\begin{tabular}{|l|l|c|}
\hline Infección & \multicolumn{1}{|c|}{ Germen } & Casos \\
\hline Neumonia $(\mathrm{n}=8)$ & Pseudomonas & 2 \\
& Staphylococcus aureus & 2 \\
& Serratia & 1 \\
& Staphylococcus haemoliticum & 1 \\
& Candida krusei & 1 \\
& Aspergillus & 1 \\
Bacteriemia $(\mathrm{n}=7)$ & Staphylococcus haemoliticum & 2 \\
& Staphylococcus epidermidis & 1 \\
& Enterobacter & 1 \\
& Pseudomonas & 1 \\
& Staphylococcus aureus & 1 \\
Infección de catéter & Escherichia coli & 1 \\
$(\mathrm{n}=4)$ & Staphylococcus haemoliticum & 2 \\
& Staphylococcus aureus & 1 \\
Infección urinaria & Escherichia coli & 1 \\
$(\mathrm{n}=2)$ & Candida krusei & 1 \\
Peritonitis $(\mathrm{n}=1)$ & Candida albicans & 1 \\
& Candida albicans & 1 \\
\hline
\end{tabular}

El adecuado mantenimiento del donante es un factor clave de todos los sucesos que se produzcan con posterioridad al trasplante; por ello el difícil manejo de estos pacientes es motivo de revisiones periódicas que ofrecen las alternativas terapéuticas más adecuadas para preservar en óptimas condiciones los órganos que se va a trasplantar ${ }^{10}$. Se tiende a adoptar estas recomendaciones mayoritariamente, por lo que el manejo de estos pacientes en general suele estar estandarizado y, concretamente en nuestra unidad, existe un protocolo escrito específico y actualizado sobre el manejo tanto hemodinámico como del medio interno de estos pacientes.

$\mathrm{Al}$ analizar los resultados obtenidos de las variables dependientes del donante, lo primero que llama nuestra atención es el hecho de que la edad no afecta al buen funcionamiento del órgano, si bien es cierto que el pico de AST es mayor en el grupo de pacientes mayores de 65 años, hecho observado por otros autores que, al igual que nosotros, tampoco han encontrado que ello afecte al funcionamiento hepático ulterior ${ }^{11}$. A la luz de los buenos resultados obtenidos con hígados procedentes de pacientes añosos ${ }^{12}$, se está generalizando su uso dentro del concepto de lo que se viene en llamar «donantes expandidos»o «donantes marginales» y se refiere a la necesidad de obtener órganos por la presión de las listas de espera, que siguen en progresión creciente incluso en España, donde el número de donaciones supera al de los países de nuestro entorno ${ }^{13}$. Nuestros resultados avalan la creencia de que los hígados procedentes de donantes mayores pueden ser utilizados con seguridad para trasplantar a nuestros pacientes.

En cuanto a la causa que motivó el fallecimiento del donante, tampoco hemos encontrado que se relacione con el mal funcionamiento del órgano, a diferencia de otros autores que señalan que la causa de muerte cerebral distinta del TCE se relaciona con un mal funcionamiento inicial del hígado trasplantado $^{14}$.

El nivel de gravedad, según nuestros datos, tampoco se ha mostrado como factor relevante, y tampoco la inestabilidad hemodinámica, como cabría esperar 
en la creencia de que un donante hipotenso puede equivaler a un hígado hipoperfundido.

Quizá el hecho más controvertido en la literatura, en cuanto a afección en el futuro hígado trasplantado, sea la hipernatremia, que históricamente se ha considerado como un factor de mal pronóstico ${ }^{15}$. Este hecho ha sido corroborado por otros autores, si bien se apunta a que la corrección de la hipernatremia previa al paso a quirófano podría evitar los efectos adversos de esta alteración electrolítica ${ }^{16}$. En nuestro caso, las alteraciones del sodio no han afectado al funcionamiento inicial del hígado, ni aun en caso de alteraciones severas con sodio en el donante por encima de $160 \mathrm{mEq} / \mathrm{l}$, si bien este dato ha sido analizado de forma aislada y no podemos descartar la posibilidad de que la suma de otras causas unidas a ésta pueda condicionar un efecto adverso. No le encontramos explicación razonable al efecto «protector» de la hipernatremia contra el síndrome de reperfusión que se desprende de nuestros datos, y creemos que no es más que un hallazgo sin significado clínico.

En algunas ocasiones, los donantes permanecen por largos períodos en nuestras unidades, lo que puede originarles infecciones de diverso tipo, con riesgo de transmisión de éstas a los receptores a través del órgano trasplantado. En la actualidad existen recomendaciones específicas acerca de qué tipo de infecciones podrían ser transmitidas al receptor y en qué supuestos debería ser tratada en el donante o incluso ser motivo de contraindicación para la donación. A este respecto, son cada vez más los trabajos que apuntan a que una bacteriemia, reconocida o no, no afecta al funcionamiento del órgano trasplantado ${ }^{17,18}$, hecho que corrobora el trabajo que presentamos, si bien cabe resaltar que, en lo que respecta a nuestros donantes con bacteriemia, ésta era conocida y estaba tratada correctamente.

Algunos autores mantienen que la prolongación del tiempo de isquemia puede ocasionar una disfunción inicial del injerto, lo que podría relacionarse con la mortalidad ${ }^{19}$, si bien nuestros datos no muestran que el tiempo de isquemia se relacione con la aparición de ninguna complicación ni con la mortalidad en el postoperatorio del trasplante. Lo ideal, a nuestro entender, hubiera sido desglosar el tiempo de isquemia y analizar de forma independiente el efecto de la isquemia fría, pero al tratarse de un estudio retrospectivo, este dato no estaba disponible en todos los casos. Sí es cierto que, según nuestra casuística, aunque el fallo primario del injerto fue poco frecuente, los casos en que se desarrolló mostraron un tiempo de isquemia superior, y lo mismo sucedió con los pacientes que requirieron retrasplante o fallecieron. Por otra parte, la supervivencia en UCI de los pacientes con fallo primario del injerto fue del $60 \%$, lo que concuerda con lo observado por otros autores, que incluso objetivan que la supervivencia de estos pacientes y la del injerto han ido aumentando de manera progresiva en los últimos años, y también se ha incrementado de manera notable el tratamiento conservador que se les ofre- $\mathrm{ce}^{20}$. En este sentido, el tratamiento de soporte hepático extracorpóreo basado en la recirculación de albúmina $\left(\mathrm{MARS}^{\circledR}\right)$ supone una considerable mejora en el tratamiento de estos pacientes y nosotros lo hemos utilizado con buenos resultados de seguridad y eficacia $^{21}$

El caso de la IRA, complicación que se sabe frecuentemente asociada al postoperatorio inmediato del trasplante hepático (un 12-42\%, según los criterios empleados para definirlo ${ }^{4,22}$ ), ha sido estudiada desde diferentes perspectivas, dada la morbimortalidad que genera, en especial en los casos en que se requiere de técnicas de reemplazo renal continuo ${ }^{23}$, así como por las repercusiones que supone el porcentaje de pacientes en que se desarrollará insuficiencia renal crónica $^{24}$.

Según se desprende de nuestros resultados, ningún factor dependiente directamente del donante se relaciona con la aparición de esta complicación en el receptor, incluidas la hipotensión o la necesidad de usar vasopresores, como cabría esperar, ni la insuficiencia renal o las alteraciones del sodio en el donante.

A pesar de que algunos autores han mostrado que el cúmulo de factores del donante que podríamos llamar «potencialmente adversos» produce algún tipo de mal funcionamiento del hígado trasplantado ${ }^{25,26}$, estudios recientes muestran que, de diez factores seleccionados como definitorios de donantes con criterios expandidos, la acumulación de incluso tres de ellos en el mismo donante no se mostró como factor predictor de mal funcionamiento del hígado, y los autores concluyeron que estos hígados podrían ser utilizados con seguridad ${ }^{27}$.

A pesar de estas evidencias, hemos de considerar que estamos ante un proceso multifactorial, en el que los factores dependientes del receptor tienen un importante papel, y son muchos los autores que señalan que la disfunción hepática tiene más probabilidades de aparecer cuando los factores dependientes del receptor (en especial, la gravedad medida por MELD) se suman a ciertos factores del donante, como la edad, el uso de vasopresores, la hipernatremia o la creatinina elevada, entre otros ${ }^{28,29}$.

En este contexto, valorar los riesgos de la suma de factores con el potencial beneficio que supone la utilización de estos donantes con criterios expandidos para reducir las listas de espera se ajusta a las perspectivas actuales ${ }^{30}$.

El hecho de que nuestro estudio se haya basado en una cohorte retrospectiva es su principal debilidad, ya que analizar sólo las variables de cuyos datos podíamos asegurar la fiabilidad ha supuesto que otras posibles variables de interés quedaran fuera del análisis. No obstante, el rigor en la selección de los datos es la única forma de asegurar la validez de un estudio con este diseño, objetivo que creemos haber cumplido.

Nosotros concluimos que los pacientes añosos y aquellos con bacteriemia conocida y tratada son adecuados donantes en cuanto a posterior funcionamiento hepático y seguridad para el receptor. 


\section{BIBLIOGRAFÍA}

1. Adam R, McMaster P, O'Grady JG, Castaing D, Klempnauer $\mathrm{JL}$, Jamieson N, et al. Evolution of liver transplantation in Europe: report of the European Liver Transplant Registry. Liver Transpl. 2003;9:1231-43.

2. Seller-Pérez G, Herrera-Gutiérrez ME, Lebrón-Gallardo M, Fernández-Ortega JF, Arias-Verdú D, Mora-Ordóñez J. Donantes de órganos en una unidad de cuidados intensivos. Med Intensiva. 2004;28:308-15.

3. Pérez-Daga JA, Santoyo J, Suárez MA, Fernández-Aguilar JA, Ramírez C, Rodríguez-Cañete A, et al. Influence of degree of hepatic steatosis on graft function and postoperative complications of liver transplantation. Transplant Proc. 2006;38:2468-70.

4. Seller-Pérez G, Herrera-Gutiérrez ME, AragonésManzanares R, Muñoz-López A, Lebrón-Gallardo M, GonzálezCorrea JA. Complicaciones postoperatorias en el trasplante hepático: su relación con la mortalidad. Med Clin (Barc). 2004; 123:321-7.

5. Knaus WA, Draper EA, Wagner DP, Zimmerman JE. APACHE II: a severity of disease classification system. Crit Care Med. 1985;13:18-29

6. Pugh RN, Murria-Lyon IM, Dawson JL, Pietroni MC, Williams R. Transection of the oesophagus for bleeding oesofageal varices. Br J Surg. 1973;60:646-9.

7. Malinchoc M, Kamath PS, Gordon FD, Peine GJ, Rank J, Borg JR. A model to predict poor survival in patients undergoing tranjugular intrahepatic portosystemic shunts. Hepatology. 2000;31:864-71.

8. Ploeg RJ, D'Alessandro AM, Knechtle SJ, Stegall MD, Pirsch JD, Hoffman RM. Risk factors for primary dysfunction after liver transplantation. A multivariate analysis. Transplantation. 1993;55:807-13.

9. Herrera-Gutiérrez ME, Seller-Pérez G, Muñoz-López A, Lebrón-Gallardo M, Aragón-González C. Soporte hepático extracorpóreo: situación actual y expectativas de futuro. Med Intensiva. 2004;28:211-8.

10. Wood KE, Becker BN, McCartney JG, D'Alessandro AM, Coursin DB. Care of the potential organ donor. N Engl J Med. 2004;351:2730-9.

11. Gastaca M, Valdivieso A, Pijoan J, Errazti G, Hernández M, González J, et al. Donors older than 70 years in liver transplantation. Transplant Proc. 2005;37:3851-4.

12. Tector AJ, Magnus RS, Chestovich P, Vianna R, Fridell JA, Milgrom ML, et al. Use of extended criteria livers decreases wait time for liver transplantation without adversely impacting posttransplant survival. Ann Surg. 2006;244:439-50.

13. ONT (Organización Nacional de Trasplantes). Memoria de actividades 2005. Trasplante hepático. Rev Esp Traspl. 2006; 15:60-80.

14. Fernández-Merino FJ, Nuño-Garza J, López-Hervás P, López-Buenadicha A, Moreno-Caparrós A, Quijano-Collazo Y, et al. Impact of donor, recipient, and graft features on the development of primary dysfunction in liver transplant. Transplant Proc. 2003;35:1793-4.

15. Avolio AW, Agnes S, Magalini SC, Foco M, Castagneto M. Importance of donor blood chemistry data (AST, serum sodium) in predicting liver transplant outcome. Transplant Proc. 1991;23: 2451-2.
16. Totsuka E, Dodson F, Urakami A, Moras N, Ishii T, Lee $\mathrm{MC}$, et al. Influence of high donor serum sodium levels on early postoperative graft function in human liver transplantation: effect of correction of donor hypernatremia. Liver Transpl Surg. 1999;5:421-8.

17. Lumbreras C, Sanz F, González A, Pérez G, Ramos MJ, Aguado JM, et al. Clinical significance of donor unrecognized bacteriemia in the outcome of solid organ transplant recipients. Clin Infect Dis. 2001;33:722-6.

18. Freeman RB, Giatras I, Falagas M, Supran S, O'Connor K, Bradley J, et al. Outcome of transplantation of organs procured from bacteriemic donors. Transplantation. 1999;68:1107-11.

19. Totsukali E, Fung JJ, Ishizawa Y, Nishimura A, Ono Toyoki $\mathrm{Y}$, Narumi S, et al. Synergistic effect of cold and warm ischemia time on postoperative graft outcome in human liver transplantation. Hepatogastroenterology. 2004;51:1413-6.

20. Varotti G, Grazi GL, Vetrone G, Ercolani G, Cescon G, Del Gaudio M, et al. Causes of early acute graft failure after liver transplantation: analysis of a 17-year single-centre experience. Clin Transplant. 2005;19:492-500.

21. Herrera-Gutiérrez ME, Seller-Pérez G, Lebrón-Gallardo M, Jiménez-Pérez M, Moreno-López J, Muñoz-López A. Seguridad y eficacia de la terapia MARS aplicada mediante monitores de TCRR. Med Intensiva. 2007;31:367-74.

22. Junge G, Schewior LV, Kohler S, Neuhaus R, Langrehr JM, Tullius S, et al. Acute renal failure after liver transplantation: incidence, etiology, therapy, and outcome. Transplant Proc. 2006; 38:723-4.

23. Gonwa TA, Mai ML, Melton LB, Hays SR, Goldstein RM, Levy MF, et al. Renal replacement therapy and orthotopic liver transplantation: the role of continuous veno-venous hemodyalisis. Transplantation. 2001:71:1424-8.

24. Lebrón-Gallardo M, Herrera-Gutiérrez ME, Seller-Pérez G, Curiel-Balsera E, Fernández-Ortega JF, Quesada-García G. Risk factors for renal dysfunction in the postoperative course of liver transplant. Liver Transplant. 2004;10:1379-85.

25. Briceño J, Marchal T, Padillo J, Solórzano G, Pera C. Influence of marginal donors on liver preservation injury. Transplantation. 2002;74:522-.6.

26. Pokorny H, Langer F, Herkner H, Schernberger R, Plochi $\mathrm{W}$, Soliman T, et al. Influence of cumulative number of marginal donor criteria on primary organ dysfunction in liver recipients. Clin Transplant. 2005;19:532-6.

27. Schemmer P, Nickkholgh A, Linz U, Gerling T, Mehrabi A, Saber P, et al. Extended donor criteria have no negative impact on early outcome alter liver transplantation: a single-center multivariate analysis. Transplant Proc. 2007:39:529-34.

28. Johnson SR, Alexopoulos S, Curry M, Hanto DW. Primary nonfunction (PNF) in the MELD era: an SRTR database analysis. Am J Transplant. 2007;7:1003-9.

29. Silberhumer GR, Pokorny H, Hetz H, Herkner H, RasoulRockenschaub S, Soliman T, et al. Combination of extended donor criteria and changes in the model for end-stage liver disease score predict patient survival and primary dysfunction in liver transplantation: a retrospective analysis. Transplantation. 2007;83:588-92.

30. Barshes NR, Horwitz IB, Franzini L, Vierling JM, Goss JA. Waitlist mortality decreases with increased use of extended criteria donor liver grafts at adult liver transplant centers. Am J Transplant. 2007;7:1265-70. 